\title{
Effects of pretreatment with intravenous palonosetron for propofol-remifentanil-based anesthesia in breast and thyroid cancer surgery: a double-blind, randomized, controlled study
}

\author{
Kye Hyeok Lee, Sung Kyu Rim, Ji Yeon Lee, So Young Lee, Su Nam Lee, Eun Ju Lee, and Ji Heui Lee
}

Department of Anesthesiology and Pain Medicine, Korean Cancer Center Hospital, Seoul, Korea

Background: We postulated that palonosetron, a novel antiemetic agent, might have the effect of alleviating injection pain from propofol and rocuronium. A double-blind, controlled study was undertaken to evaluate the effect of palonosetron on injection pain during total intravenous anesthesia and postoperative nausea and vomiting (PONV) using propofol-remifentanil in breast and thyroid cancer surgery.

Methods: Sixty patients were randomly allocated to one of two groups. Before injection of propofol and rocuronium, patients in group $S(n=30)$ received $4 \mathrm{ml}$ of saline and patients in group $\mathrm{P}(\mathrm{n}=30)$ received $75 \mu \mathrm{g}(1.5 \mathrm{ml})$ of palonosetron mixed with $2.5 \mathrm{ml}$ of saline $(\mathrm{n}=30)$. Patients were evaluated by a blinded anesthesiologist with regard to the scoring of injection pain of propofol, withdrawal response by rocuronium, PONV, shivering, postoperative pain, recall of pain, and overall satisfaction.

Results: The differences between groups in the incidence of injection pain due to propofol and rocuronium were insignificant. However, in group $\mathrm{P}$, the severity of propofol-induced injection pain $(3 \%$ vs. $33 \%, \mathrm{P}=0.003)$ and postoperative pain $(\mathrm{P}=0.038)$ was significantly lower during the first $12 \mathrm{~h}$ after surgery. No differences were observed between the groups with respect to PONV, shivering, recall of pain, and overall satisfaction.

Conclusions: We concluded that pretreatment of palonosetron was effective to reduce the severity of propofol-induced injection pain and early postoperative pain, although it did not reduce the incidence of injection pain from propofol and rocuronium. (Korean J Anesthesiol 2014; 67: 13-19)

Key Words: Pain, Palonosetron, Postoperative nausea and vomiting, Propofol.

Received: October 7, 2013. Revised: November 28, 2013. Accepted: January 9, 2014.

Corresponding author: Ji Heui Lee, M.D., Ph.D., Department of Anesthesiology and Pain Medicine, Korean Cancer Center Hospital, 75, Nowon-ro, Nowon-gu, Seoul 139-240, Korea. Tel: 82-2-970-2820, Fax: 82-2-970-2413, E-mail: jiheui0255@naver.com

(c) This is an open-access article distributed under the terms of the Creative Commons Attribution Non-Commercial License (http:// creativecommons.org/licenses/by-nc/3.0/), which permits unrestricted non-commercial use, distribution, and reproduction in any medium, provided the original work is properly cited. 


\section{Introduction}

Postoperative nausea and vomiting (PONV) is a common adverse event in patients undergoing surgeries for breast and thyroid cancers, which are the most frequent malignant neoplasms in women. It has been reported that the incidences of PONV are between 60 and $80 \%$ for mastectomy and thyroidectomy, respectively $[1,2]$. The first step for the prevention of PONV is to reduce risk factors, i.e., by the use of propofol-based anesthesia and decreased use of intraoperative $\mathrm{N}_{2} \mathrm{O}$ and postoperative opioids. Secondly, prophylactic antiemetics are available [3]. Some studies have indicated that total intravenous anesthesia using propofol and remifentanil might alleviate PONV during the early postoperative period $(<24 \mathrm{~h})$ compared to volatile anesthesia [4].

Despite the positive effects of propofol for reducing PONV, it has the major problem of causing pain and discomfort on injection. Recall of injection pain during the induction of anesthesia may have an impact on overall patient satisfaction with anesthetic care. Although the mechanism of the injection pain caused by propofol remains unclear, it has been postulated that it may be associated with a direct irritant effect or an indirect effect due to the release of pro-inflammatory mediators [5]. The mediators that are related to propofol-related injection pain may also be involved as a mechanism of pain associated with rocuronium injection [6].

Several studies have demonstrated that some 5-hydroxytryptamine $\left(5-\mathrm{HT}_{3}\right)$ receptor antagonists such as ondansetron and granisetron can reduce the incidence of propofol-related injection pain $[5,7]$. One study has reported that pretreatment with ondansetron was also effective for alleviating the pain on injection of rocuronium [6]. Palonosetron, a new, long-acting, 5- $\mathrm{HT}_{3}$ receptor antagonist, has been commonly used in our hospital for PONV following anesthesia or in the postanesthetic care unit (PACU). To our knowledge, there is no published data available regarding the effect of palonosetron on reducing propofol- and rocuronium-related injection pain. We designed this double blind, placebo-controlled, randomized study to determine the efficacy of the pretreatment with palonosetron for alleviating the injection pain of both propofol and rocuronium. We also evaluated the effect of the pretreatment with palonosetron on PONV, shivering, postoperative pain, and overall satisfaction of patients undergoing surgery for breast and thyroid cancers.

\section{Materials and Methods}

After obtaining Institutional Review Board approval of our hospital, written informed consent was obtained from all participating patients. Sixty women, aged 20 to 65 years, who were scheduled to undergo general anesthesia for breast and thyroid cancer surgery and were classified as American Society of An- esthesiology physical status of I-II, were enrolled in this study. Patients with a history of severe cardiovascular or respiratory distress, morbid obesity, drug or alcohol abuse, history of adverse medication reactions, and chronic pain, and patients who had received any antiemetics, sedatives, or analgesics within 24 $\mathrm{h}$ before surgery were excluded from the study. An 18-gauge intravenous catheter was inserted in a vein on the dorsum of the hand apart from surgical field and an infusion of Hartmann's solution was started in the ward. We excluded the patients if we could not get intravenous access at the desired vein. Patients were evaluated for the risk factors of PONV including a history of PONV, motion sickness, and nonsmoking status.

All patients were premedicated with glycopyrrolate $0.2 \mathrm{mg}$ intramuscularly $30 \mathrm{~min}$ before the induction of anesthesia. When patients arrived at the operating room, electrocardiogram, blood pressure, bispectral index (BIS), and pulse oximetry monitoring were initiated. Patients were randomly allocated to one of two groups by the investigator using a sealed envelope system. All syringes of the pretreatment drugs were prepared by an anesthetic nurse under the supervision of the investigator. The patients received the pretreatment injection of normal saline $4 \mathrm{ml}$ (group S) or palonosetron $75 \mu \mathrm{g}(1.5 \mathrm{ml})$ diluted with $2.5 \mathrm{ml}$ normal saline (group P) over a period of $30 \mathrm{~s}$ after venous occlusion at the forearm using an elastic tourniquet. Two minutes after the administration of the pretreatment drug, the tourniquet was removed and anesthetic induction with $6 \mu \mathrm{g}$ effect-site concentration (Ce) of propofol was initiated. The effect-site target controlled infusion (TCI) of propofol and remifentanil was performed by TCI pump (Orchestra Base Prima, Fresenium Vial, France). An anesthesiologist who was blinded to the nature of the pretreatment drugs asked the patients to evaluate the pain score at the injection site. Pain was graded from 0 to 3 in accordance with the design of McCrirrick A and Hunter [8], where $0=$ no pain (negative response to questioning), $1=$ mild pain (pain reported only in response to questioning without any behavioral signs), 2 $=$ moderate pain (pain reported in response to questioning and accompanied by a behavioral signs or pain reported spontaneously without questioning), and 3 = severe pain (vocal response accompanied by facial grimacing, arm withdrawal, or tears).

If the patients experienced the severe pain, the proximal portion of the injection site was gently touched and rubbed until I.V. anesthesia took effect. After loss of consciousness and upon BIS $40-60$, rocuronium bromide $(0.6 \mathrm{mg} / \mathrm{kg})$ was administered to facilitate orotracheal intubation. The independent anesthesiologist observed the patients and assessed the severity of withdrawal movements in response to rocuronium. The withdrawal score was graded as $0=$ no response, $1=$ movement at the wrist only, 2 $=$ movement involving the arm only to elbow or shoulder, and 3 = generalized response of movement in more than one extremity and reactions indicating discomfort or pain [9]. 
Anesthesia was maintained with propofol (Ce 2 to $5 \mu \mathrm{g} / \mathrm{ml}$ ), remifentanil (Ce 1 to $2.5 \mathrm{ng} / \mathrm{ml}$ ), nitrous oxide $50 \%$ in oxygen, and mechanical controlled ventilation, and rocuronium was given if required. Muscle relaxation was antagonized by glycopyrrolate $0.4 \mathrm{mg}$ and pyridostigmine $15 \mathrm{mg}$. A blinded nurse assessed the patients in the PACU for serious complications such as extrapyramidal reactions or hallucinations and illusions, if any. Note was also made of the incidence of PONV and shivering, and pain was assessed using a visual analogue scale (VAS, 0 to 10 , no pain to the most severe pain). Rescue antiemetics and analgesics for treatment of PONV and pain were ordered by the independent anesthesiologists as needed. Metoclopramide $10 \mathrm{mg}$ or ondansetron $4 \mathrm{mg}$ were intravenously administered as rescue antiemetics during the first postoperative $24 \mathrm{~h}$. If a patient required analgesics, ketorolac $30 \mathrm{mg}$ was injected intravenously.

At 12 and $24 \mathrm{~h}$ after surgery, a blinded researcher assessed allergic reactions, edema, pain at the injection site, PONV, shivering, VAS, and the use of rescue antiemetics and analgesics. All patients were asked $24 \mathrm{~h}$ postoperatively about recall of injection pain during induction of anesthesia. They were also asked to rate their satisfaction with the overall anesthetic care experience (very satisfied, satisfied, neutral, or dissatisfied).

All statistical analyses were carried out using SPSS (Windows version 17.0, SPSS Inc, Chicago, IL, USA). Power analyses indicated that 27 patients would be necessary in each group to demonstrate a reduction of pain score of 1 at an $\alpha$-value of 0.05 and power of $80 \%$. We increased the sample size to 30 patients in each group based on the possibility of a $10 \%$ dropout rate. Con-

Table 1. Patient Demographics

\begin{tabular}{lcc}
\hline & $\begin{array}{c}\text { Group S } \\
(\mathrm{n}=30)\end{array}$ & $\begin{array}{c}\text { Group P } \\
(\mathrm{n}=30)\end{array}$ \\
\hline Age (yr) & $52.9 \pm 7.0$ & $53.2 \pm 9.2$ \\
Wight (kg) & $55.7 \pm 7.2$ & $57.3 \pm 6.7$ \\
Height (cm) & $155.1 \pm 4.9$ & $157.6 \pm 6.0$ \\
Duration of surgery (min) & $87.2 \pm 18.6$ & $87.5 \pm 15.9$ \\
Risk factors & & \\
Non-smoker & $27(90)$ & $29(97)$ \\
PONV history & $0(0)$ & $0(0)$ \\
Motion sickness & $9(30)$ & $8(26.7)$ \\
Type of surgery & & \\
BCS + SLND / AD & $12(40)$ & $16(54)$ \\
TM + AD & $8(27)$ & $6(20)$ \\
Lobetomy & $8(27)$ & $6(20)$ \\
TT & $2(6)$ & $2(6)$
\end{tabular}

Data presented as mean \pm standard deviation or numbers (\%). Group S: patients who received normal saline; Group P: patients who received palonosetron. PONV: postoperative nausea and vomiting. BCS + SLND / AD: Breast conserving surgery + sentinel lymph node dissection / axillary dissection, TM + AD: Total mastectomy + axillary dissection, TT: total thyroidectomy. No statistically significant differences between the groups $(\mathrm{P}>0.05)$. tinuous variables are presented as mean \pm standard deviation and categorical variables are expressed as frequency distribution and percentage (\%). The results were statistically analyzed using Chi-square test, Fisher's exact tests, and unpaired Student's t-test when appropriate. Results were considered statistically significant when a $P$ value of $<0.05$ was obtained.

\section{Results}

All 60 patients completed the study. There were no significant differences between the two groups with regard to age, body

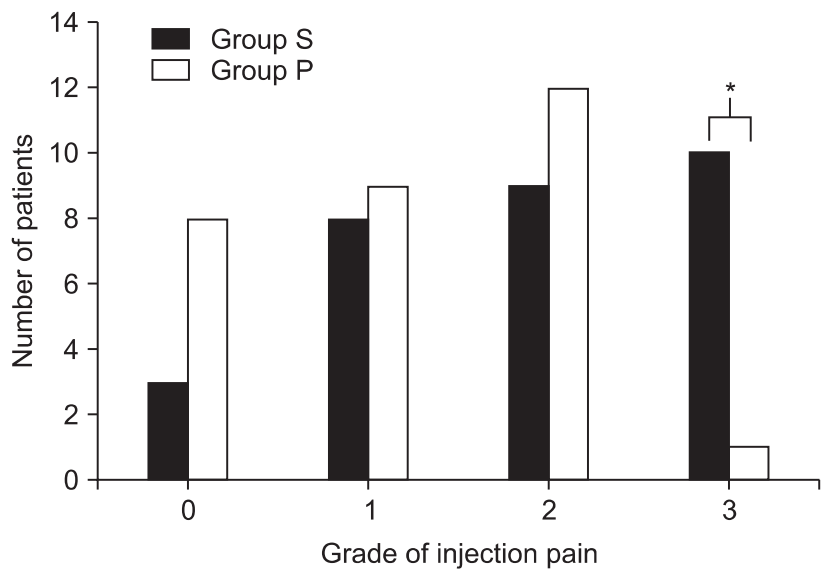

Fig. 1. Distribution of injection pain grades for propofol in the two groups. Data are presented as the number of patients. Group S: patients who received normal saline, Group P: patients who received palonosetron. Grade $0=$ no pain, $1=$ mild pain, $2=$ moderate pain, $3=$ severe pain. ${ }^{*} \mathrm{P}=0.003$, group $\mathrm{P}$ versus group $\mathrm{S}$ in grade 3 .

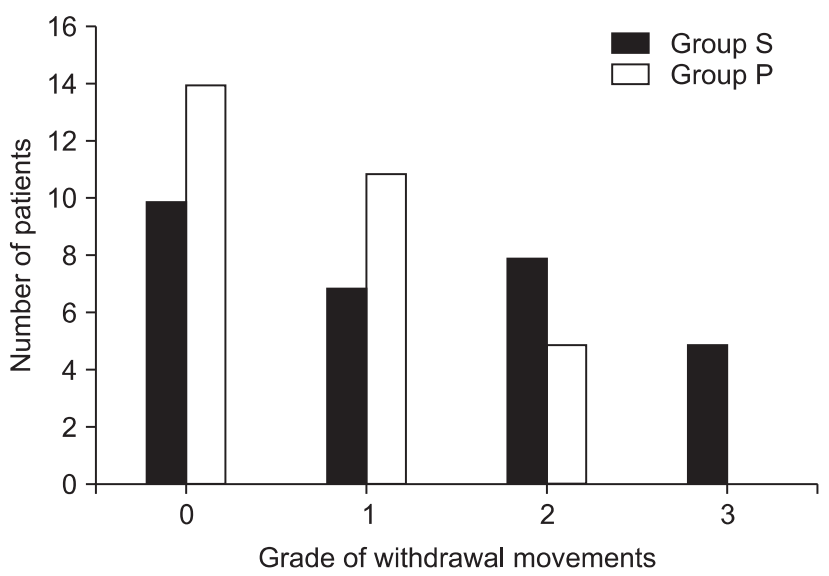

Fig. 2. Distribution of withdrawal movement grades during rocuronium injection. Data are presented as the number of patients. Group S: patients who received normal saline, Group P: patients who received palonosetron. Withdrawal grade $0=$ no response, $1=$ movement at the wrist only, $2=$ movement involving the arm only, 3 = generalized movement in more than one extremity. There are no significant differences between the groups. 
weight, height, duration of surgery, and risk factors including history of PONV, motion sickness, non-smoking, and type of surgery (Table 1). The overall incidence of pain was $90 \%$ in group $\mathrm{S}$ and $73 \%$ in group $\mathrm{P}(\mathrm{P}>0.05)$ (Fig. 1). Few patients in group $\mathrm{P}$ experienced severe pain ( $3 \%$ vs. $33 \%$; $\mathrm{P}=0.003$ ) (Fig. 1).

The incidence of withdrawal movements observed at rocuronium injection was $67 \%$ in group $\mathrm{S}$ and $53 \%$ in group $\mathrm{P}(\mathrm{P}>0.05)$ (Fig. 2). There was also no statistically significant difference between the two groups in terms of severity of rocuroniuminduced withdrawal movement.

The incidence of PONV and the requirement for rescue antiemetics was similar in the two groups during the first $24 \mathrm{~h}$

Table 2. Incidence of Postoperative Nausea and Vomiting (PONV), Shivering, and Visual Analogue Scale (VAS) Measurements of Pain with Requirement for Rescue Antiemetics and Analgesics Over the First $24 \mathrm{~h}$ Postoperatively

\begin{tabular}{ccc}
\hline Time after operation $(\mathrm{h})$ & $\begin{array}{c}\text { Group S } \\
(\mathrm{n}=30)\end{array}$ & $\begin{array}{c}\text { Group P } \\
(\mathrm{n}=30)\end{array}$ \\
\hline PACU & & \\
PONV & $6(20)$ & $4(13)$ \\
Antiemetics & $5(16)$ & $3(10)$ \\
Shivering & $12(40)$ & $11(37)$ \\
VAS & $7.6 \pm 1.4$ & $6.5 \pm 1.6^{*}$ \\
Analgesics & $25(83)$ & $20(67)$ \\
1-12 & & \\
PONV & $9(30)$ & $5(17)$ \\
Antiemetics & $3(10)$ & $4(13)$ \\
Shivering & $3(10)$ & $2(7)$ \\
VAS & $3.2 \pm 1.4$ & $2.4 \pm 1.2^{*}$ \\
Analgesics & $12(40)$ & $8(27)$ \\
12-24 & & \\
PONV & $7(23)$ & $5(17)$ \\
Antiemetics & $3(10)$ & $1(3)$ \\
Shivering & $0(0)$ & $1(3)$ \\
VAS & $1.2 \pm 0.7$ & $1.2 \pm 0.6$ \\
Analgesics & $4(13)$ & $5(17)$ \\
\hline
\end{tabular}

Data presented as mean \pm standard deviation or numbers (\%). PACU: postanesthesia care unit. ${ }^{*} \mathrm{P}<0.05$ Group $\mathrm{P}$ compared with Group S.

Table 3. Incidence of Recall of Injection Pain by Propofol and Overall Satisfaction of Patients

\begin{tabular}{lcc}
\hline & $\begin{array}{c}\text { Group S } \\
(\mathrm{n}=30)\end{array}$ & $\begin{array}{c}\text { Group P } \\
(\mathrm{n}=30)\end{array}$ \\
\hline $\begin{array}{l}\text { Recall of pain } \\
\text { Patient satisfaction }\end{array}$ & $11(37)$ & $6(20)$ \\
$\quad$ Very satisfied & $9(30)$ & $12(40)$ \\
Satisfied & $18(60)$ & $18(60)$ \\
Neutral & $2(7)$ & $0(0)$ \\
Dissatisfied & $1(3)^{*}$ & $0(0)$
\end{tabular}

Data presented as numbers (\%). There were no statistically significant differences between groups $(\mathrm{P}>0.05)$. One patient in the saline group reported dissatisfaction due to the injection pain during induction of anesthesia. after surgery (Table 2). VAS values for postoperative pain were statistically lower in group $\mathrm{P}$ while in the PACU $(\mathrm{P}=0.011)$ and during first $12 \mathrm{~h}$ after surgery $(\mathrm{P}=0.038)$ (Table 2$)$. The incidence of shivering and the requirements for rescue analgesics were not significantly different between the two groups (Table 2). There were no complications such as extrapyramidal reaction, hallucination, illusion, and changes at the injection site. Recall of injection pain was similar in the two groups and there were no significant differences in patient satisfaction ratings, although one patient in the saline group reported dissatisfaction due to injection pain experienced during the induction of anesthesia (Table 3).

\section{Discussion}

This study demonstrated that, compared to saline, pretreatment with palonosetron with simultaneous venous occlusion was efficacious for reducing the severity of the pain occurring during injection of propofol, although it did not reduce the overall incidence of injection pain associated with propofol and rocuronium. Palonosetron reduced the level of postoperative pain during the first $12 \mathrm{~h}$ after surgery. PONV during the first postoperative day are rare in patients undergoing total intravenous anesthesia using propofol-remifentanil for breast and thyroid cancer surgery, so we could not distinguish the efficacy of palonosetron for the prevention of early PONV.

Pain on injection of anesthetics may be an important cause of patient dissatisfaction during the perioperative period. One patient in our saline group recalled induction of anesthesia as the most painful part of the perioperative period and reported dissatisfaction with the overall anesthetic care. The pain on injection of propofol is ranked seventh among the 33 most problematic low-morbidity perioperative outcomes [10]. An incidence of pain of about $60 \%$ on injection of propofol without any preventive measures has been reported [11].

The mechanism of propofol-related injection pain is not established, but it has been suggested that it is due to endothelial irritation resulting from the chemical phenol properties of propofol along with activation of the kallikrein-kinin system that is known to play a role in inflammation [5]. Propofol injection, therefore, may be associated with the release of histamine, bradykinin, and other inflammation-mediating substances, and Borgeat and Kwiatkowkski [12] have demonstrated that the mechanism of rocuronium-associated pain may be related to a direct irritant effect on the kinin cascade. The nature of the pain on injection of rocuronium is similar to the nature of the pain induced by the injection of propofol. Lidocaine is the most common agent given before injection to prevent propofol- or rocuronium-related injection pain, although the protection is not complete [6]. 
Ye et al. [13] have reported that ondansetron has a 15-foldhigher potency as a local anesthetics, than lidocaine injected under the skin via a dual mechanism of sodium channel blockade and $5 \mathrm{HT}_{3}$ receptor antagonism. Intrathecal ondansetron has been shown to reduce the nociceptive response of dorsal horn neurons in the rat spinal cord [14]. Ondansetron has also been shown to combine with $\mu$ opioid receptors in humans and show agonist activity [15], and $5-\mathrm{HT}_{3}$ receptors have been shown to be located in the nociceptive fibers of the dorsal horn and in the peripheral nervous system and to modulate nociceptive pathways [16]. Antagonism of $5-\mathrm{HT}_{3}$ receptors in the spinal cord is associated with an antinociceptive effect for acute pain evoked by formalin stimulus [17]. As a result of its multifunction as a sodium channel blocker, $\mu$ opioid agonist, and $5-\mathrm{HT}_{3}$ receptor antagonist, ondansetron should be useful to reduce the pain produced by propofol and rocuronium injection [6]. Other $5 \mathrm{HT}_{3}$ receptor antagonists, such as granisetron and ramosetron, have also been shown to alleviate the injection pain of propofol compared to the placebos $[7,18]$.

The $5-\mathrm{HT}_{3}$ receptor antagonist palonosetron has a greater binding affinity and longer half-life than other $5-\mathrm{HT}_{3}$ receptor antagonist [19]. The unique pharmacokinetics of palonosetron have been associated with clinical outcomes including better prevention of chemotherapy-induced nausea and vomiting compared with other $5-\mathrm{HT}_{3}$ drugs [20]. We presumed that palonosetron, as a more refined $5-\mathrm{HT}_{3}$ receptor antagonist, could relieve the injection pain associated with propofol and rocuronium by a similar mechanism. Our results demonstrated a high incidence of pain in all patients: $90 \%$ in the saline group and $73 \%$ in the palonosetron group, but the rate of severe pain was significantly lower in palonosetron group (3\%) compared to the saline group (33\%). Palonosetron was less successful in reducing the overall incidence of pain in comparison studies with ondansetron vs. placebo ( $25 \%$ vs. $50 \%)$ and granisetron vs. placebo (15\% vs. 60 $\%)$ pretreatment [5,7]. This may be explained by the different molecular structure of palonosetron, which also interacts with $5-\mathrm{HT}_{3}$ receptors at different sites than the older $\mathrm{HT}_{3}$ receptor antagonists [21]. Rojas et al. [21] have reported that palonosetron has allosteric interactions and positive cooperativity with $5-\mathrm{HT}_{3}$ receptors and that these characteristics were not present in the other $5-\mathrm{HT}_{3}$ receptor antagonists. These may produce the pharmacological differences noted in clinical studies comparing palonosetron to other $5-\mathrm{HT}_{3}$ receptor antagonists.

We chose a 2-min interval between the injection of palonosetron and the infusion of propofol with the presumption that this period might be sufficiently longer vs. previous studies with granisetron and ondansetron [5,7]. The reduced effectiveness of palonosetron for injection pain in comparison to the other agents may also be explained by a delayed onset of action, which is a pharmacokinetic character of the long-acting agent. There is no prior evidence or study regarding the onset of action of palonosetron, although Lummis and Thompson [22] have reported that association of palonosetron at both $5-\mathrm{HT}_{3 \mathrm{~A}}$ and $5-\mathrm{HT}_{3 \mathrm{~B}}$ receptors was compared in 30 min with $\mathrm{t}_{1 / 2}$ values of 4.1 and 2.0 min, respectively.

In the present study, pretreatment with palonosetron did not prevent withdrawal movements due to rocuronium injection. The exact mechanism of the injection pain of rocuronium is not still clearly understood. The pain may be induced by low $\mathrm{pH}$ or by the release of local mediators such as kinin, histamine, and other pro-inflammatory substances [23]. Our study indicated that palonosetron was not effective in preventing the injection pain leading to withdrawal movement of arms, which may be explained by the same reasons presumed in the results of the incidence propofol-associated injection pain.

With regard to postoperative pain, our results demonstrated that the palonosetron group had reduced pain during assessment in the PACU and during the first $12 \mathrm{~h}$ after surgery. The $5-\mathrm{HT}_{3}$ receptor is known to have pronociceptive abilities and to relate to the spinobulbospinal loop that is stimulated by superficial neurokinin 1 receptor-expressing neurons [24], and McClean et al. [25] have reported that ondansetron was effective in alleviating chronic neuropathic pain. To date, there are no published data available regarding the antinociceptive effect of palonosetron other than one study showing that palonosetron had no effect on modulation of mechanical allodynia in a postoperative rat pain model [26].

We omitted premedication with sedatives or anxiolytic agents such as midazolam and tried to assess the recall of the patients of pain and discomfort during propofol or rocuronium injection. Although there was an unacceptably high incidence of injection pain in the patients in the present study, dissatisfaction with the overall anesthetic care, including recall of pain was rare among the patients in either group. We used light touch and rubbing at the injection site after grading pain if the patients experienced severe pain during the pain assessment. Kim et al. [27] reported that rubbing and light touch significantly decreased moderate and severe pain, although they did not have a reduced incidence of pain.

We found that $40 \%$ of the patients in the saline group and $36.7 \%$ in the palonosetron group had postoperative shivering and that the pretreatment with palonosetron had no antishivering effect. These findings were similar to those of a previous study conducted in patients who underwent laparoscopic surgery under total intravenous anesthesia (TIVA) [28]. In that study, Jo et al. [28] speculated that the ineffectiveness of palonosetron against shivering was related to smaller doses or the failure of the $5-\mathrm{HT}_{3}$ antagonist against acute remifentanil-induced tolerance.

In general, 5- $\mathrm{HT}_{3}$ receptor antagonists are well tolerated with 
few side effects including headache, dizziness, and constipation. In our study, there were no adverse effects such as extrapyramidal reactions or hallucination and illusion, which have occurred rarely after the use of ondansetron [29].

There was a low incidence of PONV during the first $24 \mathrm{~h}$ after surgery in the present study, different from results of previous studies regarding PONV associated with breast and thyroid surgery $[1,2]$. The incidence of PONV is known to be influenced by patient characteristics, type of surgical procedure, anesthesia technique, and postoperative analgesics [3]. Generally, female gender, a history of motion sickness, previous PONV, and nonsmoking are risk factors associated with PONV [3], and we had no differences in these risk factors between the two groups in the present study. Kim et al. [4] reported that the incidence of PONV during the first $24 \mathrm{~h}$ after endoscopic thyroidectomy was $14.6 \%$ in a TIVA group compared to $51 \%$ in a balanced anesthesia group. Their result revealed a lower incidence of PONV in endoscopic thyroidectomy compared to open thyroidectomy through the antiemetic effect of TIVA. We also observed the morbidity of PONV only during the first $24 \mathrm{~h}$ after surgery and could assert that TIVA using propofol-remifentanil reduced the incidence of early PONV for this study. We used only NASAIDs as rescue analgesics and avoided the use of the opioids, that may increase the incidence of PONV.

We failed to show an efficacy of palonosetron for PONV, although a previous study demonstrated excellent prevention
PONV by palonosetron during a postoperative period of $72 \mathrm{~h}$ [30]. Our results may need to be interpreted with consideration of other clinical factors, particularly the single-center, smaller study, in which the low overall incidence of PONV may also be related to the unusual proficiency of surgeons masking the nature of emetogenic procedures. Also, although the sample size of this study was acceptable for the analysis of injection pain induced by anesthetics, it may have been insufficient for the study of PONV. We did not observe PONV after the first $24 \mathrm{~h}$ after surgery or the long-lasting antiemetic effect of palonosetron, which may be efficient in late PONV.

In conclusion, it was shown in this study, that pretreatment with palonosetron was effective for alleviating the severity of pain during injection of propofol as well as early postoperative pain. There has been a low incidence of PONV in patients who received TIVA using propofol and remifentanil for breast and thyroid cancer surgery. Therefore, the efficacy of palonosetron for the prevention of PONV was not clear during the first postoperative $24 \mathrm{~h}$.

\section{Acknowledgments}

We thank Department of Otorhinolaryngology (Dr. Lee GH, Dr. Lee BC, Dr. Lee MC, Dr Choi IJ) and General Surgery (Dr. No WC, Dr. Kim HA, Dr. Kim EK), Korea Cancer Center Hospital for their support of data collection.

\section{References}

1. Reihnér E, Grunditz R, Giesecke K, Gustafsson LL. Postoperative nausea and vomiting after breast surgery: efficacy of prophylactic ondansetron and droperidol in a randomized placebo-controlled study. Eur J Anaesthesiol 2000; 17: 197-203.

2. Ewalenko P, Janny S, Dejonckheere M, Andry G, Wyns C. Anti-emetic effects of subhypnotic doses of propofol after thyroidectomy. Br J Anaesth 1996; 77: 463-7.

3. Fujii Y. Management of postoperative nausea and vomiting in women scheduled for breast cancer surgery. J Anesth 2011; 25: 917-22.

4. Kim GH, Ahn HJ, Kim HS, Bang SR, Cho HS, Yan M, et al. Postoperative nausea and vomiting a after endoscopic thyroidectomy: total intravenous vs balanced anesthesia. Korean J Anesthesiol 2011; 60: 416-21.

5. Ambesh SP, Dubey PK, Sinha PK. Ondansetron pretreatement to alleviate pain on propofol injection: a randomized, controlled, doubleblinded study. Anesth Analg 1999; 89: 197-9.

6. Reddy MS, Chen FG, Ng HP. Effect of ondansetron pretreatment on pain after rocuronium and propofol injection: a randomized, doubleblind controlled comparison with lidocaine. Anaesthesia 2001; 56: 902-5.

7. Singh DK, Jindal P, Singh G. Comparative study of attenuation of the pain caused by propofol intravenous injection, by granisetron, magnesium sulfate and nitroglycerine. Saudi J Anaesth 2011; 5: 50-4.

8. McCrirrick A, Hunter S. Pain on injection of propofol: the effect of injectate temperature. Anaesthesia 1990; 45: 443-4.

9. Shevchenko Y, Jocson JC, McRae VA, Stayer SA, Schwartz RE, Rehman M, et al. The use of lidocaine for preventing the withdrawal associated with the injection of rocuronium in children and adolescents. Anesth Analg 1999; 88: 746-8.

10. Macario A, Weinger M, Truong P, Lee M. Which clinical anesthesia outcomes are both common and important to avoid? The perspective of a panel of expert anesthesiologists. Anesth Analg 1999; 88: 1085-91.

11. Jalota L, Kalira V, George E, Shi YY, Hornuss C, Radke O, et al. Prevention of pain on injection of propofol: systemic review and metaanalysis. BMJ 2011; 342: d1110.

12. Borgeat A, Kwiatkowski D. Spontaneous movements associated with roucuronium: is pain on injection the cause? Br J Anaesth 1997; 79: 382-3. 
13. Ye JH, Mui WC, Ren J, Hunt TE, Wu WH, Zbuzek VK. Ondansetron exhibits the properties of a local anesthetic. Anesth Analg 1997; 85: 1116-21.

14. Ali Z, Wu G, Kozlov A, Barasi S. The role of 5HT3 in nociceptive processing in the rat spinal cord: results from behavioral and electrophysiological studies. Neurosci Lett 1996; 208: 203-7.

15. Gregory RE, Ettinger DS. 5HT3 receptor antagonists for the prevention of chemotherapy induced nausea and vomiting a comparison of their pharmacology and clinical efficacy. Drugs 1998; 55: 173-89.

16. Sommer C. Is serotonin hyperalgesic or analgesic? Curr Pain Headache Rep 2006; 10: 101-6.

17. Jeong CY, Bae HB, Park HC, Choi JL, Yoon MH. Evaluation of the role of 5-hydroxytryptamine receptor subtypes in the regulation of nociceptive transmission in the rat spinal cord. Korean J Anesthesiol 2004; 47: 856-61.

18. Lee HY, Kim SH, So KY. Prevention of microemulsion propofol injection pain: a comparison of a combination of lidocaine and ramosetron with lidocaine or ramosetron alone. Korean J Anesthesiol 2011; 61: 30-4.

19. Yang LP, Scott LJ. Palonosetron: in the prevention of nausea and vomiting. Drugs 2009; 69: 2257-78.

20. Gralla R, Lichinitser M, Van der Vegt S, Sleeboom H, Mezger J, Peschel C, et al. Palonosetron improves prevention of chemotherapyinduced nausea and vomiting following moderately emetogenic chemotherapy: results of a double-blind randomized phase III trial comparing single doses of palonosetron with ondansetron. Ann Oncol 2003; 14: 1570-7.

21. Rojas C, Stathis M, Thomas AG, Massuda EB, Alt J, Zhang J, et al. Palonosetron exhibits unique molecular interactions with the 5-HT3 receptor. Anesth Analg 2008; 107: 469-78.

22. Lummis SC, Thompson AJ. Agonists and antagonists induce different palonosetron dissociation rates in 5-HT3A and 5-HT3B receptors. Neuropharmacology 2013; 73: 241-6.

23. Blunk JA, Seifert F, Schmelz M, Reeh PW, Koppert W. Injection pain of rocuronium and vecuronium is evoked by direct activation of nociceptive nerve endings. Eur J Anaesthesiol 2003; 20: 245-53.

24. Faerber L, Drechsler S, Ladenburger S, Gschaidmeier H, Fischer W. The neuronal 5-HT3 receptor network 20 years of research-evolving concepts in management of pain and inflammation. Eur J Pharmacol 2007; 560: 1-8.

25. McCleane GJ, Suzuki R, Dickenson AH. Does a single intravenous injection of the 5-HT3 receptor antagonist ondansetron have an analgesic effect in neuropathic pain? A double-blinded, placebo-controlled cross-over study. Anesth Analg 2003; 97: 1474-8.

26. Jung KT, Yoon MH, Lee HY, Yu BY, Kim DK, Lim KJ. Effects of palonosetron, a 5-HT3 receptor antagonist, on mechanical allodynia in a rat model of postoperative pain. Korean J Pain 2013; 26: 125-9.

27. Kim SY, Jeong DW, Jung MW, Kim JM. Reduction of propofol injection pain by utilizing the gate control theory. Korean J Anesthesiol 2011; 61: 288-91.

28. Jo YY, Kwak HJ, Lee MG, Lim OK. Effect of palonosetron on postanesthetic shivering after propofol-remifentanil total intravenous anesthesia. J Anesth 2013; 27: 535-40.

29. Kumar N, Hu WT. Extrapyramidal reaction to ondansetron and propofol. Mov Disord 2009; 30: 312-3.

30. Kovac AL, Eberhart L, Kotarski J, Clerici G, Apfel C. A randomized, double-blind study to evaluate the efficacy and safety of three different doses of palonosetron versus placebo in preventing postoperative nusea and vomiting over a 72-hour period. Anesth Analg 2008; 107: 439-44. 